
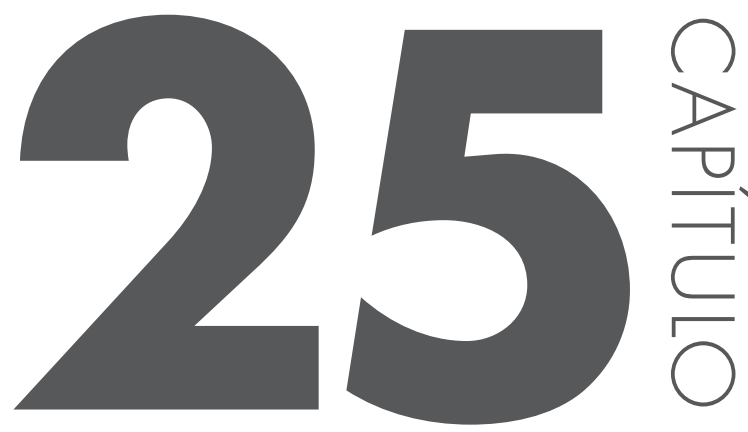

\title{
OS MÉTODOS NA CONSTRUC̣ÃO DO CONHECIMENTO
}

\author{
Maldonado, Priscila Souza ${ }^{1 *}$; Mendonça, Marcelo Rodrigues ${ }^{2}$ \\ 1 Mestranda do Programa de Pós-Graduação em Geografia-RC/UFG - Bolsista CAPES \\ 2 Professor do Programa de Pós-Graduação em Geografia-RC e IESA/UFG \\ * email: priscila.geografia@gmail.com
}

\section{RESUMO}

Este artigo se propõe a discutir as principais características dos métodos científicos e sua utilização. Sabendo que a escolha do método é guiada por convicções políticas e ideológicas dos pesquisadores e pesquisadoras, procuramos evidenciar quais são as marcas de cada método esclarecendo o que cada discurso pode oferecer ao desvendamento da Ciência. Assim, trataremos dos três métodos reconhecidos pela cientificamente, são eles: o Positivismo, a Fenomenologia e o Materialismo Histórico Dialético.

Palavras-chave: Método; Pesquisa Cientifica; Geografia 


\section{A GEOGRAFIA ENQUANTO CIÊNCIA}

Este artigo é fruto das leituras e debates propostos no âmbito do Curso de Pós Graduação em Geografia da Universidade Federal de Goiás - Regional Catalão, onde foram oferecidas disciplinas de reflexão sobre o método na pesquisa Geográfica.

Pretende-se apresentar aqui as principais características que constituem os métodos analíticos e fazer as devidas relações com o a pesquisa que pretendemos encaminhar durante o Mestrado. Nesse sentido, as reflexões aqui contidas estão intimamente relacionadas à pesquisa de Mestrado, que se encontra em fase final, portanto, trata-se de um debate introdutório que pretende ser elaborado e aprofundado ao longo das investigações.

Toda pesquisa científica carrega as características do pesquisador ou pesquisadora que a desenvolvem. O método utilizado em determinada investigação cientifica é sempre uma escolha política. De acordo com essas afirmações, podemos dizer que, não há neutralidade na esfera da produção do conhecimento, e mais, que esse é um espaço onde acontecem constantes e importantes disputas políticas.

A cientificidade ou não das ciências humanas tem provocado debates que levam a reflexão sobre os métodos de pesquisa. As discussões sobre o método são importantes, pois, afirmam as divergências dos discursos científicos e o caráter político e ideológico dos mesmos. A epistemologia é a teoria do conhecimento que se constitui enquanto um processo.

A Geografia tem sido criticada constantemente em relação a sua cientificidade, ou seja, se é uma Ciência, então qual é o seu método? Muitos estudos de epistemologia têm sido feitos até então com objetivo de conseguirem respostas satisfatórias para essa dúvida. A Geografia é uma Ciência que sempre se atentou em entender como o homem transforma ou cria o espaço onde vive.

Por um longo tempo a Geografia se manteve descritiva e empirista. Durante muito tempo a Geografia foi definida como uma descrição da paisagem. Com a emergência da Geografia Teorético-quantitativa troca-se paisagem por geometria, buscando padrões de organização do espaço. Assim, os geógrafos quantitativos começaram a usar o positivismo na Geografia que era reconhecido com um método verdadeiramente cientifico, assim, tinha o objetivo de tornar a Geografia uma Ciência de fato. Passaram a aplicar técnicas matemático-estatísticas e por em prática as regras do "método científico", testar hipóteses, aplicar experimentação, desenvolver dados e busca de leis e teorias era fundamental. 
Nas décadas de 1960 e 1970 se aprimorou uma nova tendência na Geografia que se colocava como crítica em relação aos geógrafos tradicionais e neopositivistas, focados na filosofia marxista e preocupados com as injustiças sociais e com a atuação política passaram a desenvolver o Método Dialético. Desse modo, começaram a se envolver com diferentes problemas, como: o modo de produção, as contradições do sistema capitalista, a visão de totalidade, a ideia de essência, entre outras.

Já na década de 1970 surge uma nova corrente geográfica conhecida como Geografia Humanística, mais direcionada para a psicologia, com o objetivo de entender os sentimentos das pessoas ou de grupos sociais referentes ao lugar onde habitavam, e compreender as relações afetivas. Aprimoraram o uso do método fenomenológico intensificando suas investigações na experiência de vida, os pontos de vistas mais íntimos das pessoas, suas emoções, seus anseios, desejos, medos, entre outras ações.

Sabe-se que um paradigma é definido pela soma de ideias, teorias e doutrinas organizadas através de um método distinguindo as tendências cientificas. $\mathrm{O}$ entendimento das teorias e suas ligações com os paradigmas são importantes, pois, revela a maneira como se propõe a interpretação das diversas leituras possíveis da realidade. $\mathrm{O}$ método é o procedimento que se aproxima de uma atividade cientifica e sua estruturação, que contém elementos incorporados historicamente, levou ao estabelecimento de três métodos reconhecidos pela comunidade cientifica: o Positivismo, o Materialismo Histórico Dialético e a Fenomenologia.

\section{O MÉTOdO E A PRODUÇÃO DO CONHECIMENTO}

Nessa parte, busca-se fazer uma breve discussão em relação aos métodos reconhecidos cientificamente frisando as suas principais características, para que fique evidente suas diferenciações. Assim, essa é uma concisa introdução que nos ajudará a definir e apontar de onde estamos partindo, ou seja, a nossa escolha metodológica.

Existem muitos autores e autoras com diferentes perspectivas em relação ao significado da palavra "método". O método pode ser entendido como: o caminho epistemológico percorrido na tentativa de chegar à compreensão do movimento do real. Uma estrutura teórica, um conjunto organizado de ideias, que funciona como uma ferramenta de interpretação da realidade.

Spósito (2004) se refere a método, como um “[...] instrumento intelectual e racional que possibilite a apreensão da realidade objetiva pelo investigador, 
quando este pretende fazer uma leitura dessa realidade e estabelecer verdades científicas para sua interpretação. (SPÓSITO, 2004, p. 23).

Não se pode confundir ou mesmo tratar como sinônimos, método e metodologia. Ambos fazem parte da pesquisa cientifica, mas, diferentemente do método, a metodologia diz respeito aos procedimentos, às etapas, à forma como será encaminhada a pesquisa, ou seja, pressupõe um conjunto de práticas que a pesquisadora ou o pesquisador se propõe a realizar para efetivar a pesquisa.

A metodologia a ser utilizada em uma pesquisa, assim como o método, é sempre uma escolha. São os sujeitos (pesquisador/pesquisadora) que fazem as escolhas, e toda escolha é carregada de subjetividade e intencionalidade. Logo, não há nenhuma dúvida, de que, o discurso de neutralidade na pesquisa cientifica é totalmente falacioso.

Entende-se, portanto, que ao nos decidirmos aventurar no universo da pesquisa é necessário que se faça opções teóricas e que nos posicionemos politicamente. Essa decisão nunca deve significar uma camisa de força, nem mesmo fechar o campo da crítica ou a possibilidade de mudar de ideia. No entanto, deve-se ficar atentos, pois, a inconsistência teórico-metodológica pode resultar em miscelâneas grosseiras de teorias que divergem radicalmente.

Os métodos apontados como sendo coerentes por possuírem características que historicamente relacionam-se a procedimentos e teorias disseminadas pela comunidade científica são: o Positivismo, o Materialismo Histórico Dialético e a Fenomenologia. Cada um deles possui características próprias e são produto do desenvolvimento secular da Ciência.

A Ciência Moderna, tal como se conhece, é nascida nas bases iluministas e institucionalizada a partir do positivismo e da normatividade. A ideia de ciência está ligeiramente associada a um conjunto de saberes e conhecimentos formais ou empírico-formais, muito relacionados às Ciências Exatas. Essa associação que se faz comumente é dotada de sentido, pois, historicamente, o modelo lógico-formal, através das premissas do positivismo, foi predominante. Existe uma tendência a estender esse método ao conjunto das disciplinas científicas, com intuito de uniformizar e padronizar as identidades epistemológicas. (GOMES, 1996).

No método Positivista, o saber cientifico é sempre produto de um conjunto de regras determinadas, que serviriam para legitimar o conhecimento gerado. Esse método explica os fenômenos, a partir do raciocínio lógico, que é a condição para todo conhecimento válido. O raciocínio lógico procura garantir através de uma série de condutas, a objetividade. As premissas da neutralidade e da objetividade científica, pressupõem que as respostas para um mesmo fenômeno tenham que ser sempre as mesmas, independente de quem seja a pesquisadora ou o pesquisador. Podemos dizer também que, de acordo com o Positivismo, o rigor 
é um dos critérios fundamentais para a validade formal e a legitimidade científica.

Diferentemente, a Fenomenologia, consiste num método e numa forma de pensar, nos quais a 'intencionalidade da consciência' é considerada. Assim também, se estima a percepção advinda das experiências vividas, que é considerada etapa metodológica fundamental na busca de romper a cisão ou a hierarquização: sujeito-objeto. A Fenomenologia busca descrever os fenômenos (aquilo que se dá imediatamente) e renuncia a tomar como ponto de partida uma teoria do conhecimento. É o sujeito que descreve o objeto e suas relações, a partir do seu ponto de vista, depois dele se apropriar intelectualmente. $\mathrm{O}$ peso que se confere ao sujeito (pesquisador/a) faz com que o objeto, muitas vezes, chegue a ficar em segundo plano, correndo o risco de se tornar apenas o elemento a ser analisado. (SPÓSITO, 2004).

Já o método Materialismo Histórico Dialético rompe com a ideia de dicotomia, que é o alicerce do pensamento lógico-formal, pois, uma de suas premissas é a interação dos pares dialéticos que não estão em oposição, mas, estão contidos um no outro num movimento que é contraditório. A busca por desvendar esse movimento é justamente o exercício do método Materialista Dialético.

Por não se tratar de um método idealista, mas, sim materialista, parte da realidade objetiva e da investigação das relações sociais de produção que edificam a sociedade humana. Dessa forma, consegue estabelecer e explicar as tendências do modo de produção capitalista, com vistas à superação dessas relações.

Por isso, esse é um método altamente propositivo, questiona a necessidade e o papel da ciência no mundo capitalista e assim, a partir do movimento interacional da relação teoria e prática sustenta sua metodologia na práxis revolucionária e na análise da luta de classes, que aparece enquanto dimensão histórica do método.

Karl Marx, o principal pensador que contribuiu para a sistematização do método Materialista Histórico Dialético, aponta para a importância da atuação revolucionária, prático-crítica, pois, é exatamente na prática que o homem tem que demostrar a verdade de seu pensamento. O problema do pensamento humano não é um problema da teoria, mas sim, um problema prático. "A vida social é essencialmente prática. Todos os mistérios que desviam a teoria para o misticismo encontram sua solução racional na prática humana e na compreensão desse prática”. (MARX, 1999, p. 07). Por conseguinte, não se consegue chegar a complexidade das relações sociais, a partir da análise do indivíduo de maneira isolada.

Uma das características que exemplificam o caráter do conceito de prática, nesse contexto, está na máxima de que não basta interpretar o mundo de forma diferente, mas sim, modificá-lo. Assim se expressa uma das máximas do 
pensamento marxista, que tem haver essencialmente com o método analítico em que se encontra.

Ao se referir a obra de Marx, Berman (1986), afirma que:

O que de mais valioso ele nos tem a oferecer, hoje, não é o caminho que permita sair das contradições da vida moderna, e sim um caminho mais seguro e mais profundo que nos coloque exatamente no cerne dessas contradições. (BERMAN, 1986, p. 125).

Por isso, ao se obscurecer as relações de antagonismo de classes, que são o principal motor da história, esta se negando a contradição e fechando os olhos para os conflitos e para milhares de homens e mulheres que estão vivendo no limite da exploração e da opressão de classes, de gênero e racial.

Sabe-se que estamos bem longe de findarmos essa preocupação em relação às bases filosóficas da Ciência. Essa síntese objetivou esboçar compreensões e reconhecer a importância do estudo em teoria e epistemologia para o amadurecimento enquanto pesquisadoras e pesquisadores, principalmente no contexto da Ciência Geográfica.

\section{CONSIDERAC̣ÕES FINAIS}

A Geografia que hoje conhecemos tem suas origens no século XIX e, como Ciência, se estabeleceu nas bases do positivismo, mas vê-se também que todos os métodos em algum momento tiveram sua importância para esta Ciência. Ao longo da história da Geografia, que desde o surgimento tenta se firmar enquanto Ciência, percebe-se que existem transições no que se refere a produção do conhecimento e que de acordo com os momentos históricos e com as necessidades de desenvolver outros métodos foi escrevendo uma historia de diferentes teorias e leituras do real.

O método tem uma relação direta com a visão de mundo e a posição políticaideológica do pesquisador e/ou pesquisadora, sendo que a escolha do método perpassa pelo momento histórico, pela postura política e pelas escolhas de quem vai pesquisar. A importância do método na pesquisa é como o esqueleto para o corpo, é ele que vai dar a sustentação e articulação necessária ao processo de produção do conhecimento.

Desse modo, é importante que sejam viabilizadas pesquisas que tenham a epistemologia como tema central na Geografia, para que seja possível aprofundar o debate em relação as bases conceituais e teóricas que dão sustentação aos métodos, bem como suas utilizações na Ciência Geográfica. 


\section{Tiłle: THE METHODS IN THE CONSTRUCTION OF KNOWLEDGE}

\section{Abstract}

This article aims to discuss the main characteristics of scientific methods and their use. Knowing that the choice of method is guided by political and ideological convictions of male and female researchers, we try to show what are the marks of each method explaining what each discourse may provide clarification of Science. Thus, we will treat the three scientifically recognized methods, they are: Positivism, Phenomenology and Dialectical Materialism History.

Keywords: Method. Scientific Research. Geography. 


\section{REFERÊNCIAS}

ALVES-MAZZOTTI, Alda Judith; GEWANDSZNAJDER, Fernando. 0 Método nas Ciências Naturais e Sociais: Pesquisa Quantitativa e Qualitativa. São Paulo: Pioneira Thompson Learning, 2002.

ANTUNES, Ricardo. Os sentidos do trabalho: ensaio sobre a afirmaç̃ão e a negação do trabalho. São Paulo: Boitempo, 1999.

2004.

. (Org.). A dialética do trabalho: escritos de Marx e Engels. São Paulo: Expressão Popular,

BERMAN, Marshall. Tudo que é sólido desmancha no ar: a aventura da modernidade. São Paulo: Companhia das Letras, 1986.

CAPEL, Horacio. Filosofia y ciência en la geografia comtemporânea. Espanha: Barcanova, 1981.

CASTRO, Iná de. Geografia: conceitos e temas. Rio de Janeiro: Bertrand Brasil, 1995.

GOMES, Paulo César. Geografia e modernidade. Rio de Janeiro: Bertrand Brasil, 1996.

LACOSTE, Yves. A Geografia? Isso serve, em primeiro lugar, para fazer a guerra. Campinas: Papirus, 1993.

LOWY, Michael. As aventuras de Karl Marx contra o Barão de Munchhausen - marxismo e positivismo na sociologia do conhecimento. São Paulo: Cortez, 1994.

MORAES, Antonio Carlos Robert. Ideologias geográficas: espaço, cultura e política no Brasil. São Paulo: Hucitec, 1996.

MOREIRA, Ruy. 0 que Geografia. São Paulo: Brasilienses, 2012. (Colecão Primeiros Passos; 48).

MARX, Karl. Teses sobre Feuerbach (1845). Versão para ebooks. Rocket Edition, 1999. Disponível em: EbooksBrasil.com. Acesso em: maio de 2013.

SPÓSITO, Eliseu Savério. Geografia e Filosofia. Contribuições para o ensino do pensamento geográfico. São Paulo: Editora UNESP, 2004. 